\title{
Experimental characterization of a hermetic scroll expander for use in a micro-scale Rankine cycle
}

\author{
V Lemort*, S Declaye, and S Quoilin \\ Thermodynamics Laboratory, University of Liège, Liège, Belgium \\ The manuscript was received on प and was accepted after revision for publication on प】.
}

DOI: $10.1177 / 0957650911413840$

\begin{abstract}
This paper presents the results of an experimental study carried out on a prototype of a hermetic scroll expander, integrated into a gas cycle test rig, whose working fluid is HFC-245fa. This system is designed to test only the performance of the expander. It is made up mainly of a scroll compressor, a scroll expander, a heat exchanger, and a by-pass valve. The latter is used to adjust the pressure ratio imposed to the expander. The expander was originally a compressor designed for heat pump applications and is characterized by a nominal power input of $2.5 \mathrm{kWe}$. Performance of the expander is evaluated in terms of isentropic effectiveness and filling factor as functions of the main operating conditions. The study also investigates the impact of oil mass fraction on the expander performance. Maximum overall isentropic effectiveness of 71.03 per cent is measured, which is partly explained by the good volumetric performance of the machine. Using the experimental data, parameters of a semi-empirical simulation model of the expander are identified. This model is used to analyse the measured performance of the expander. Finally, a polynomial empirical model of the expander is proposed for fast and robust simulations of organic Rankine cycle systems.
\end{abstract}

Keywords: scroll expander, hermetic, organic rankine cycle, ORC

\section{INTRODUCTION}

The Rankine cycle is particularly suitable for recovering energy from low-grade heat sources such as industrial waste heat, for cooling down of mechanical equipment, and for recovering the heat from internal combustion engines (cooling water and exhaust gas) or produced by solar concentrators. The working fluid can be either water or an organic component, such as a refrigerant or a hydrocarbon, which allows exploiting lower-temperature heat sources.

In terms of available displacements, the scroll machine is particularly well adapted to small-scale Rankine cycle applications (electrical powers lower than $25 \mathrm{kWe}$ ). Also, the scroll machine offers major advantages such as reliability and robustness (reduced number of moving parts), simplicity (no

*Corresponding author: Thermodynamics Laboratory, University of Liège, Campus du Sart Tilman, B49, B-4000 Liège, Belgium. email: vincent.lemort@ulg.ac.be admission and discharge valves), low rotational speeds, and the ability to handle high pressure ratios. However scroll expanders are not commercially available yet and the available prototypes are usually developed for the purpose of laboratory experiments. Those prototypes are generally built by modifying a scroll compressor to make it run in reverse. The basic process of a scroll expander is shown in Fig. 1. During the suction process, a pocket of fluid is trapped in the suction chamber. The suction chamber evolutes into two expansion chambers after one shaft revolution. Similarly, expansion chambers become discharge chambers once they come into contact with the discharge line of the machine.

Until now, mainly open-drive scroll expanders have been investigated. Yanagisawa et al. [1] carried out an experimental study on an oil-free scroll-type air expander. Measured performance was analysed by comparison with the prediction of an analytical model of the expander. They observed that the 


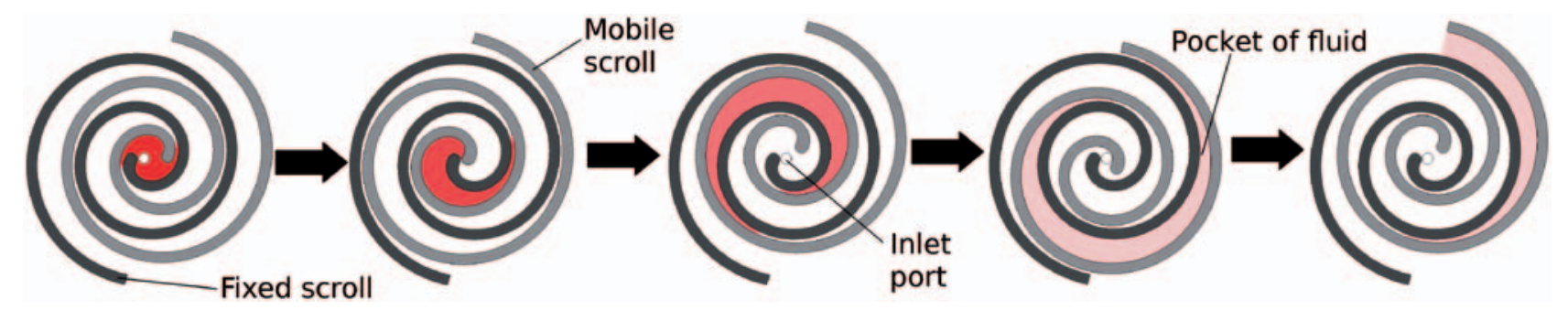

Fig. 1 Working principle of a scroll expander

performance is lowered greatly by the mechanical losses accompanying the orbiting motion, but leakage losses become significant as the rotational speed decreases. Mechanical losses result from two sources: the main bearing and the auxiliary crank mechanisms that support the revolving motion of the orbiting scroll; and friction between the orbiting and the fixed scrolls. They observed that the mechanical loss torque is neither a function of the suction pressure nor of the rotational speed. Volumetric effectiveness of 76 per cent and adiabatic effectiveness of 60 per cent were achieved under condition of suction pressure $6.5 \mathrm{bar}$ gauge and rotational speed of $2500 \mathrm{r} / \mathrm{min}$.

Manzagol et al. [2] studied a cryogenic scroll expander used for a 101/h helium liquefier. The expander was tested on a Brayton cycle refrigerator and reached an isentropic effectiveness of 50 to 60 per cent for inlet gas conditions of $35 \mathrm{~K}$ and $7.0 \mathrm{bar}$.

Huff and Radermacher [3] analysed, through simulation, three positive displacement mechanisms for their potential as expansion machines in a $\mathrm{CO}_{2}$ system: reciprocating piston, rotary piston, and scroll. They showed that the performance of the scroll mechanism is the most dependent on the leakage gap size.

Xiaojun et al. [4] investigated the possibility to recover work in a fuel cell by means of a scroll expander. The work produced by the expander can be provided to the compressor. The expander was numerically simulated and a prototype of the expander was tested. It was shown that the leakages strongly impact on the volumetric performance of the machine.

Hugenroth et al. [5] developed a novel approach to implementing a gas Ericsson cycle heat pump. The concept uses liquid flooding of the compressor and expander to approach isothermal compression and expansion processes. Scroll machines were selected owing to their ability to compress and expand a mixture of oil and gas.

Aoun and Clodic [6] carried out an experimental investigation on an oil-free scroll-type vapour expander. The original gasket was replaced by a hand-made polytetrafluoroethylene (PTFE) gasket, more adapted for high-temperature applications (about $190^{\circ} \mathrm{C}$ ) and showing lubricating properties. Maximal achieved volumetric effectiveness was 46 per cent with the original gasket and 63 per cent (at rotation speed of $2850 \mathrm{r} / \mathrm{min}$ and pressure ratio of 4) with the PTFE gasket. Maximal isentropic effectiveness was 48 per cent at rotation speed of $2000 \mathrm{r} / \mathrm{min}$ and pressure ratio of 3.8. Better volumetric performance was achieved with the expander operating with air rather than with steam. This could have been due to the high operating temperature of the steam that resulted in metal expansion and could have led to larger axial and radial clearances.

Peterson et al. [7] evaluated the performance of a micro-scale organic Rankine cycle (ORC) working with HCFC-123 and using a kinematically rigid scroll expander with a displacement of $12 \mathrm{~cm}^{3}$ and a built-in volume ratio of 4.57 . The expander was fed in oil by means of an external gear pump coupled to a centrifugal oil separator at the outlet of the expander. The cycle operated between a heat source of 165$183^{\circ} \mathrm{C}$ and a heat sink of $22.5^{\circ} \mathrm{C}$. The power developed by the expander ranged between 187 and $256 \mathrm{~W}$ and the system efficiency reached 7.2 per cent. They showed that the critical component, in terms of impact on the system efficiency, was the expander, with a measured isentropic effectiveness ranging between 45 and 50 per cent. Such low performance was due to excessive internal leakages, which is characteristic of this type of expander.

The authors also investigated both experimentally and numerically a prototype of an open-drive scroll expander derived from an air compressor and fed with HCFC-123 [8]. Mechanical isentropic effectiveness of 68 per cent was achieved. The study stressed that the large internal leakage, characteristic of a kinematically rigid configuration (no compliant), largely penalizes the expander performance. Also, the tested machine was not tight, which was a major drawback given the price of the working fluid and the environmental concern. The authors evaluated the influence of the performance of the expander on that of the ORC heat engine [9]. More recently, they extended their experimental and modelling analysis to fluids HFC-245fa and HFE-7000 [10]. 
For some applications, such as micro-combined heat and power (CHP), it would be more convenient to have an expander producing directly electrical power, instead of mechanical power. This justifies the interest for better characterizing the performance of a hermetic scroll expander. Such a machine is expected to show better volumetric performance than kinematically rigid expanders $[\mathbf{7}, \mathbf{8}]$ and to be perfectly tight.

Only a few scientific works on this type of machine were found in the open literature. Zanelli and Favrat [11] tested a prototype of hermetic scroll expandergenerator fed with refrigerant HFC-134a. The maximal achieved isentropic effectiveness was 65 per cent and the power produced by the machine ranged from 1.0 to $3.5 \mathrm{~kW}$. Kane et al. [12] designed, built, and tested a prototype of hybrid solar thermal power plant associating solar collectors, CHP engines, and two superposed ORCs (HCFC-123 and HFC-134a), equipped with hermetic scroll expanders. Heat source temperature ranged between 130 and $165^{\circ} \mathrm{C}$ and heat sink temperature was about $7^{\circ} \mathrm{C}$. Produced electric power ranged from 4 to $10 \mathrm{kWe}$, the maximum achieved efficiency of the cascade ORCs was 14 per cent, and the effectiveness of the expanders ranged from 50 to 68 per cent according to the pressure ratio.

More recently, Wang et al. [13] measured the performance a compliant scroll expander derived from an existing compressor and characterized by a displacement of $6.5 \mathrm{~cm}^{3}$ and a built-in volume ratio of 2.5. The machine was tested in a gas cycle with HFC134a for different pressure ratios (2.65 to 4.84) and rotational speeds (2005 to $3670 \mathrm{r} / \mathrm{min}$ ). Their prototype of expander allowed for control of the sealing pressure, by pressurizing the chamber atop the fixed scroll. They also showed that the scroll sealing pressure was a critical parameter to maximize the expander performance. Maximum mechanical isentropic effectiveness reached 77 per cent. Maximum shaft power was about $1 \mathrm{~kW}$. They observed that the impact of the rotational speed and pressure ratio was limited.

The purpose of the present study was to investigate through experimentation and simulation the performance of a hermetic scroll expander. The first part of the paper presents an experimental study carried out on such a machine fed with HFC-245fa. The evolution of the performance of the machine with main operating parameters is presented. Among others, the impact of the quantity of lubricating oil is investigated. In the second part, a semi-empirical simulation model is presented, calibrated, and validated based on experimental data. The model is used to quantify the different losses in the machine. Finally, a simplified dimensionless model of the machine, for fast and robust simulation of ORC systems, is proposed.

\section{EXPERIMENTAL INVESTIGATION}

\subsection{Description of the test rig}

A 'gas cycle' test rig was built to test the performance of the expander with fluid HFC-245fa. This rig (simpler, less bulky, and cheaper to build than the entire Rankine cycle system) is made up mainly of a scroll compressor, a scroll expander, a water-cooled heat exchanger, and a by-pass valve. A simplified representation of the cycle described by the working fluid is given in Fig. 2: the fluid, in vapour phase, is successively compressed $(1 \rightarrow 2)$, expanded $(2 \rightarrow 3)$, and cooled down $(3 \rightarrow 1)$. A heat exchanger could have been integrated at the outlet of the compressor to adjust the expander inlet temperature.

The expander was originally a hermetic compressor designed for heat pump applications and is characterized by a nominal electrical consumption of $2.5 \mathrm{kWe}$. The displacement of the machine in compressor mode is approximately $12 \mathrm{~m}^{3} / \mathrm{h}$ and the built-in volume ratio is close to 3.0.

The selection of the working fluid was based on a numerical comparison of the performance of an ORC system working with four different fluids [14]. That study indicated that, for heat source and heat sink temperatures of about $150^{\circ} \mathrm{C}$ and $20^{\circ} \mathrm{C}$, best performance of the system is achieved by n-pentane, followed successively by HCFC-123, HFC-245fa, and HFC-134a. Refrigerant HFC-245fa was finally selected, considering that $\mathrm{n}$-pentane is flammable and HCFC-123 will be phased out in a near future.

A detailed representation of the rig is given in Fig. 3. The expander supply and exhaust pressures were regulated by controlling simultaneously the by-pass

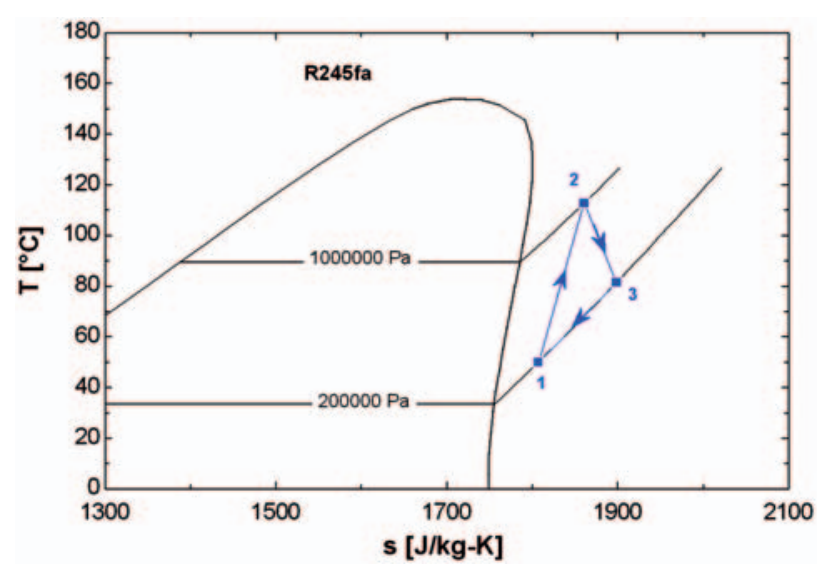

Fig. $2 T-s$ diagram of the gas cycle 


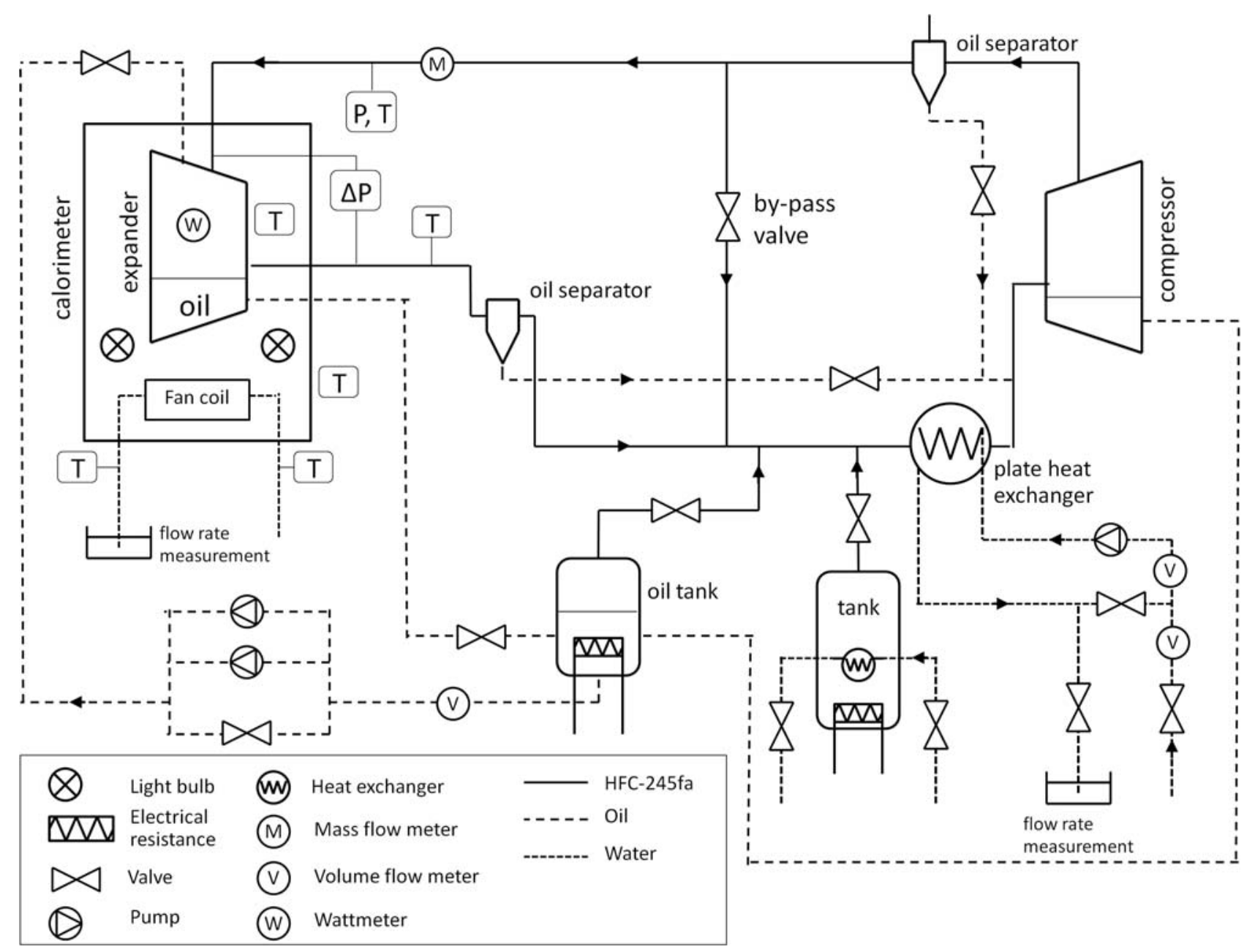

Fig. 3 Schematic representation of the test rig

valve opening and the charge of fluid in the system. Refrigerant could be added or withdrawn by condensation or vaporization inside a tank connected to the main refrigerant circuit and equipped with both a cooling coil and an electrical resistance.

The test rig was designed in such a way as to be able to measure the oil mass flowrate at the expander supply. This was achieved by separating the oil from the refrigerant at the compressor exhaust and sending it back to the expander supply through an external oil circuit. Main components of this circuit are an oil flow meter, two gear pumps in parallel arrangement, an oil tank with an electrical heater (used for separating the gas entrained by the oil coming from the compressor oil sump), and a needle valve (used to regulate the oil flowrate supplied to the expander).

The expander was installed inside a calorimeter to determine the heat transfer to the ambient. A constant air temperature is maintained inside the calorimeter by simultaneously controlling the fan coil water flowrate and the power supply of two light bulbs.
The heat balance over the calorimeter box is given by

$$
-\dot{Q}_{\text {cal }, \mathrm{amb}}+\dot{W}_{\text {fan }}+\dot{W}_{\text {bulb }}-\dot{H}_{\text {coil }}+\dot{Q}_{\text {exp }, \text { man }}=0
$$

where

$\dot{Q}_{\mathrm{cal} \text {, amb }}$ is the heat transfer between the calorimeter box and the outside environment (W)

$\dot{W}_{\text {fan }}$ is the fan power $(\mathrm{W})$

$\dot{W}_{\text {bulb }}$ is the light bulb power (W)

$\dot{H}_{\text {coil }}$ is the enthalpy flowrate of the cooling water (W)

$\dot{Q}_{\text {exp, man }}$ is the heat transfer between the expander and the environment inside the calorimeter box (W).

Calibration of the calorimeter box consisted in developing a given heating power inside the box and measuring the temperature difference between the inside and outside environments. The calibration of the calorimeter box allowed determination of the heat transfer coefficient between the box and the outside environment. The identified value was $3.2 \mathrm{~W} / \mathrm{K}$. This value was used further during the tests to estimate the ambient heat losses $\dot{Q}_{\text {exp, amb }}$. 


\subsection{Measurement devices}

Temperatures were measured by means of T-type thermocouples. The reference temperature was given by a mixture of ice and water. Pocket-mounted thermocouples were used to measure the gas temperatures and contact thermocouples to measure the surface temperatures.

The expander supply pressure was measured by means of an absolute pressure transducer. The expander exhaust pressure was determined by measuring the pressure difference over the expander with a differential pressure transducer. A Coriolis mass flow meter was used to measure the mass flowrate through the expander. Measuring ranges and accuracy of the different measuring devices are given in Table 1.

\subsection{Overall measured performance}

In total, a series of 27 performance points were achieved. Several independent variables were available for the control of the system during the experimental campaign. They were the expander supply and exhaust pressures, the supply temperature, and the quantity of circulating oil. Dependent variables resulted from the choice of the independent variables. These variables were the fluid mass flowrate, the electrical power produced by the expander, and the exhaust temperature. Minimum and maximum values of all these variables are given in Table 2. In order to check the accuracy of the measurements, the following heat balance was performed on the expander

$$
\begin{aligned}
\text { residue }= & \dot{M}_{\text {meas }} \cdot\left(h_{\mathrm{su}}-h_{\mathrm{ex}}\right)+\dot{M}_{\mathrm{oil}} \cdot c_{\mathrm{oil}} \\
& \cdot\left(T_{\mathrm{oil}, \mathrm{su}}-T_{\mathrm{ex}}\right)-\dot{Q}_{\mathrm{exp}, \mathrm{amb}}-\dot{W}_{\mathrm{el}, \text { meas }}
\end{aligned}
$$

where

$\dot{M}_{\text {meas }}$ is the measured mass flowrate $(\mathrm{kg} / \mathrm{s})$

$h_{\mathrm{su}}$ is the enthalpy of the fluid at the supply of the expander $(\mathrm{J} / \mathrm{kg})$

$h_{\mathrm{ex}}$ is the enthalpy of the fluid at the exhaust of the expander $(\mathrm{J} / \mathrm{kg})$

$\dot{M}_{\text {oil }}$ is the oil mass flowrate through the expander $(\mathrm{kg} / \mathrm{s})$

$c_{\text {oil }}$ is the specific heat capacity of oil $(\mathrm{J} / \mathrm{kg}-\mathrm{K})$

$T_{\text {oil, su }}$ is the oil temperature at the supply of the expander $\left({ }^{\circ} \mathrm{C}\right)$

$T_{\text {ex }}$ is the temperature at the outlet of the expander $\left({ }^{\circ} \mathrm{C}\right)$

$\dot{W}_{\text {el, meas }}$ is the measured electrical power (W)

For the 27 measurements points the residue was lower than 8.9 per cent of the total enthalpy drop.

The overall performance of the expander was evaluated in terms of overall isentropic effectiveness, defined as the ratio between the measured electrical power output and the isentropic expansion power (equation (2)). This isentropic effectiveness is an electrical effectiveness (i.e. the electrical output power divided by the isentropic expansion power).

$$
\varepsilon_{\mathrm{s}, \text { meas }}=\frac{\dot{W}_{\mathrm{el}, \text { meas }}}{\dot{W}_{\mathrm{s}}}=\frac{\dot{W}_{\mathrm{el}, \text { meas }}}{\dot{M}_{\text {meas }} \cdot w_{\mathrm{s}}}=\frac{\dot{W}_{\mathrm{el}, \text { meas }}}{\dot{M}_{\text {meas }} \cdot\left(h_{\mathrm{su}}-h_{\mathrm{ex}, \mathrm{s}}\right)}
$$

where

$h_{\mathrm{ex}, \mathrm{s}}$ is the calculated isentropic enthalpy: $h_{\mathrm{ex}, s}=$ $h\left(\mathrm{R} 245 \mathrm{fa}, p=p_{\mathrm{ex}}, s=s_{\mathrm{su}}\right)$

Volumetric performance of the machine was quantified through the filling factor, defined as the ratio of the measured mass flowrate and the mass flowrate theoretically displaced by the expander (equation (4))

$$
\varphi_{\text {meas }}=\frac{\dot{M}_{\text {meas }} \cdot v_{\mathrm{su}}}{\dot{V}_{\mathrm{s}}}
$$

\begin{tabular}{|c|c|c|c|c|c|c|c|c|}
\hline & \multicolumn{8}{|c|}{ Measured variable } \\
\hline & \multicolumn{3}{|l|}{ Temperatures } & \multicolumn{2}{|l|}{ Pressures } & \multicolumn{2}{|l|}{ Flowrates } & \multirow{2}{*}{$\frac{\text { Electrical power }}{\dot{W}_{\exp }}$} \\
\hline & $\overline{T_{\mathrm{r}, \mathrm{su}, \exp }}$ & $T_{\mathrm{r}, \mathrm{ex}, \exp }$ & $T_{\text {surf,exp }}$ & $\overline{P_{\mathrm{r}, \mathrm{su}, \exp }}$ & $\Delta P_{\mathrm{r}, \exp }$ & $\bar{M}_{\mathrm{r}, \exp }$ & $\dot{V}_{\text {oil }}$ & \\
\hline $\begin{array}{l}\text { Range } \\
\text { Uncertainty }\end{array}$ & $\begin{array}{l}-200 \text { to }+300^{\circ} \mathrm{C} \\
0.5 \mathrm{~K}\end{array}$ & $\begin{array}{l}-200 \text { to }+300^{\circ} \mathrm{C} \\
0.5 \mathrm{~K}\end{array}$ & $\begin{array}{l}-200 \text { to }+300^{\circ} \mathrm{C} \\
0.5 \mathrm{~K}\end{array}$ & $\begin{array}{l}0-25 \text { bar } \\
0.125 \text { bar }\end{array}$ & $\begin{array}{l}0-20 \text { bar } \\
0.1 \text { bar }\end{array}$ & $\begin{array}{l}0.25-13 \mathrm{~kg} / \mathrm{min} \\
\pm 1 \%\end{array}$ & $\begin{array}{l}1.25 \mathrm{l} / \mathrm{min} \\
\pm 0.05 \mathrm{l} / \mathrm{min}\end{array}$ & $\begin{array}{l}0-3 \mathrm{~kW} \\
15 \mathrm{~W}\end{array}$ \\
\hline
\end{tabular}

\begin{tabular}{|c|c|c|c|c|c|c|c|c|c|}
\hline & \multicolumn{4}{|c|}{ Independent variables } & \multicolumn{3}{|c|}{ Dependent variables } & \multicolumn{2}{|c|}{ Performance indicators } \\
\hline & $\overline{P_{\text {su }} \text { (bar) }}$ & $P_{\text {ex }}$ (bar) & $T_{\text {su }}\left({ }^{\circ} \mathrm{C}\right)$ & $x_{\text {oil }}(\%)$ & $\bar{M}_{\text {meas }}(\mathrm{g} / \mathrm{s})$ & $\dot{W}_{\mathrm{el}, \text { meas }}(\mathrm{W})$ & $T_{\text {ex,meas }}\left({ }^{\circ} \mathrm{C}\right)$ & $\varepsilon_{\mathrm{s}, \text { meas }}$ & $\varphi_{\text {meas }}$ \\
\hline Minimum & 6.72 & 1.69 & 92 & 0.8 & 38.35 & 298 & 68.4 & 0.3428 & 1.024 \\
\hline Maximum & 16.06 & 3.19 & 139 & 3.2 & 121.2 & 2032 & 100 & 0.7103 & 1.101 \\
\hline
\end{tabular}

Table 1 Measuring ranges and accuracy of the different measurement devices

Table 2 Ranges of measured variables 
The evolution of the overall isentropic effectiveness with the pressure ratio is shown in Fig. 4, for the whole tests. As already shown by Zanelli and Favrat [11], this effectiveness decreases sharply for the small pressure ratios due to over-expansion losses and decreases for the larger pressure ratios due to under-expansion losses. In the current tests, a maximum isentropic effectiveness of 71.03 per cent was achieved.

Error bars are associated with calculated uncertainties. Provided measurements are uncorrelated and random, the uncertainty $U_{Y}$ on the variable $Y$ is calculated as a function of the uncertainty $U_{X_{i}}$ on each measured variable $X_{i}$ by equation (5) [14]

$$
U_{Y}=\sqrt{\sum_{i}\left(\frac{\partial Y}{\partial X_{i}}\right)^{2} U_{X_{i}}^{2}}
$$

The evolution of the filling factor with the supply pressure is given in Fig. 5 for a series of points characterized by an exhaust pressure ranging from 1.98 to 3.84 bar and a supply temperature ranging from 92 to

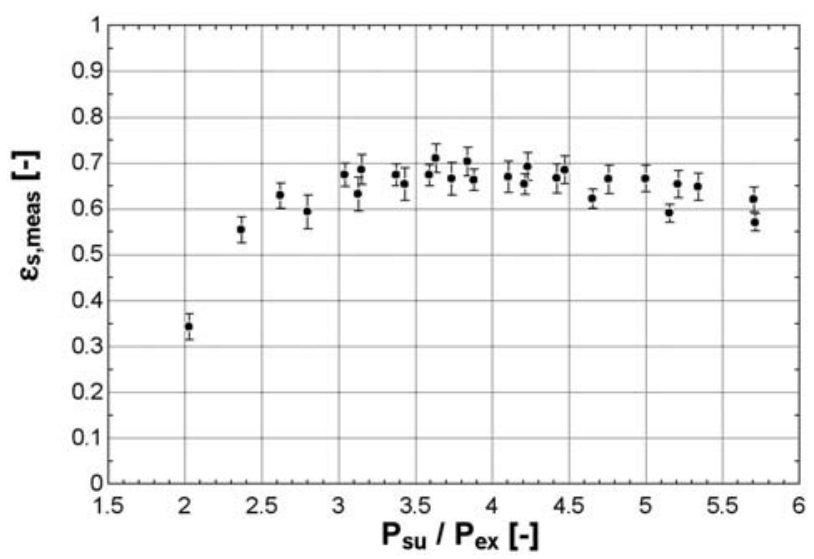

Fig. 4 Isentropic effectiveness versus pressure ratio

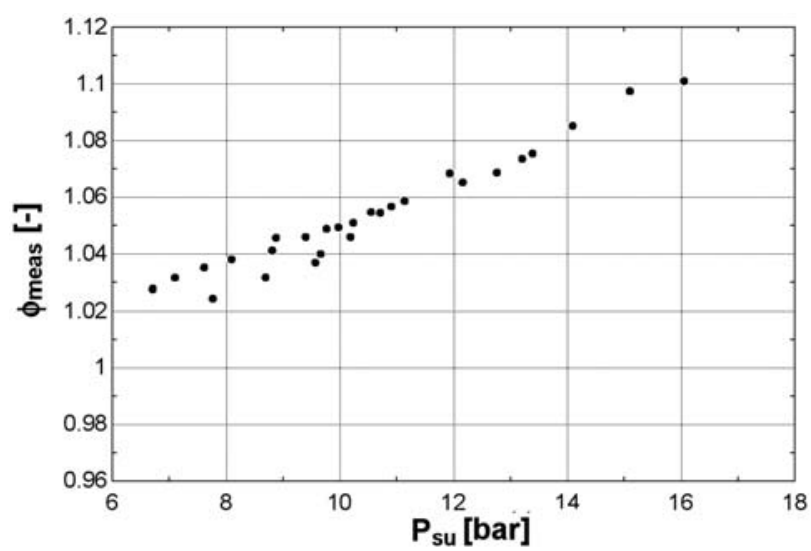

Fig. 5 Filling factor versus supply pressure $139^{\circ} \mathrm{C}$. The slight increase of the filling factor with pressure might be explained by the increase of internal leakages.

Figure 6 shows that the electrical power developed by the machine increases monotonically with the system pressure ratio. It shows that, although operated higher than its internal pressure ratio (around 3), the discharge process still produces useful work for the expander. Scattering is due to the variation of the other operating conditions, such as the supply pressure and temperature.

\subsection{Impact of oil mass fraction on performance}

In the tests presented previously, the oil mass fraction was maintained between 0.7 and 2.3 per cent. Additional tests were carried out with larger oil mass fractions to investigate the impact of the oil quantity on the expander performance. Figure 7 shows the evolution of the expander overall isentropic effectiveness with the oil mass fraction (for a pressure ratio of $4.218 \pm 0.065$ and a supply temperature

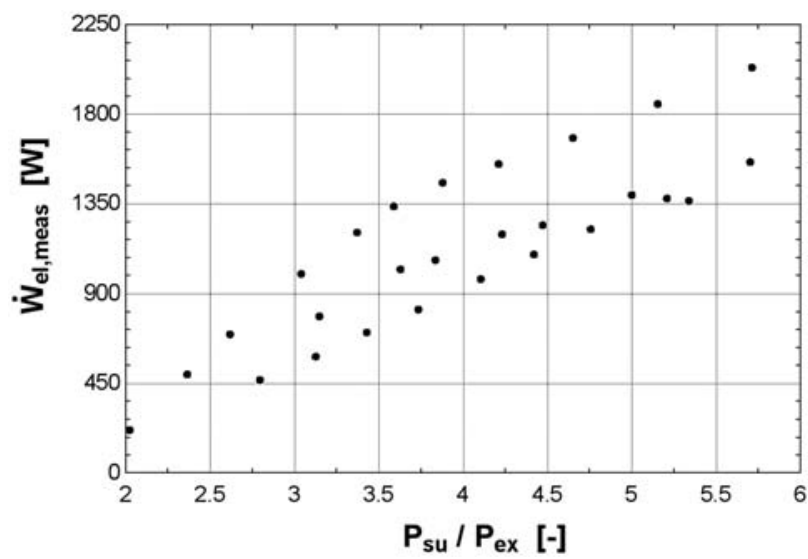

Fig. 6 Electrical power versus pressure ratio

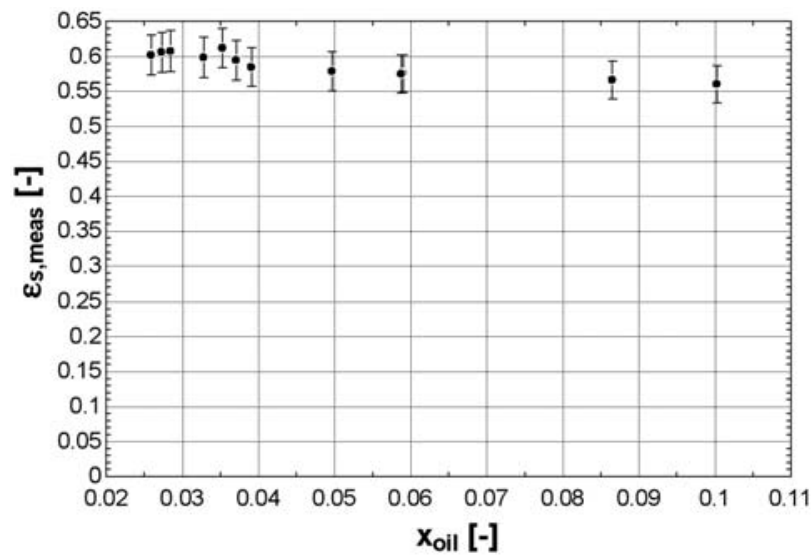

Fig. 7 Isentropic effectiveness versus oil mass fraction 
of $92.0 \pm$

$\left.1.5^{\circ} \mathrm{C}\right)$. It can be observed that the isentropic effectiveness decreases with the oil quantity. Further investigation is needed to identify with certainty the underlying reason (among others, the increase of the supply pressure drops or viscous losses).

As shown in Fig. 8, the filling factor correlates fairly well with the supply pressure and the oil mass fraction. As mentioned in section 2.3, the increase of the filling factor with the supply pressure is due to the increasing impact of the leakages. On the contrary, the decrease of this factor with the oil mass fraction can be due to either the better ability of the oil to seal the leakage paths or the larger supply pressure drops. It should however be noted that the range of variation of the filling factor is quite limited, making it impossible to draw any accurate conclusion. The polynomial law should therefore be taken as a general trend, not a firm rule.

\section{MODELLING A HERMETIC SCROLL EXPANDER}

\subsection{Description of the model}

A semi-empirical model of an open-drive scroll expander previously proposed by the authors [8] has been slightly adapted to represent the performance of a hermetic machine. The proposed model, also very close to the hermetic scroll compressor model proposed by Winandy et al. [15], retains the main physical phenomena inherent to the machine. Only the main features of the model are recalled in this paper.

The evolution of the fluid through the expander is decomposed into the following consecutive steps (Fig. 9): an adiabatic pressure drop (su $\rightarrow$ su,1) and an isobaric cooling down by contact with the metal

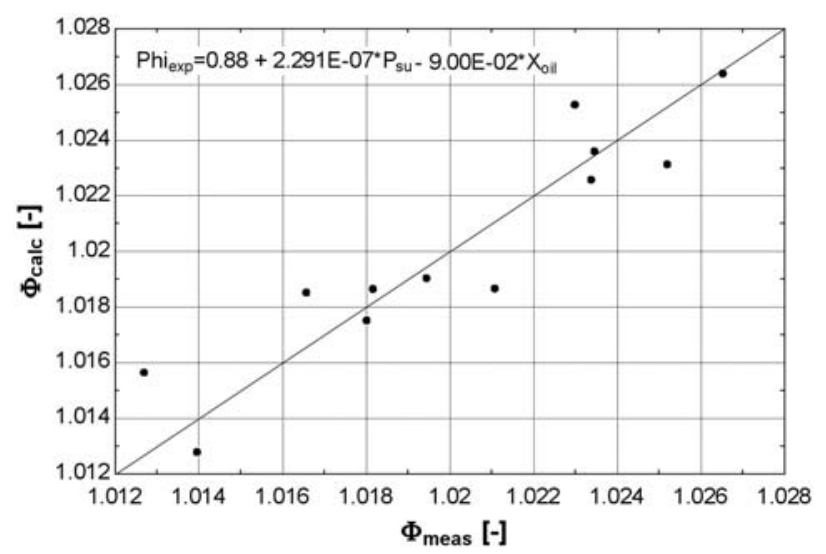

Fig. 8 Filling factor versus supply pressure and oil fraction mass of the machine (su, $\rightarrow$ su,2) during the suction process; an isentropic expansion to the 'adapted' pressure imposed by the built-in volume ratio of the machine (su, $2 \rightarrow$ ad) and an adiabatic expansion at a constant machine volume (ad $\rightarrow \mathrm{ex}, 2)$; an adiabatic mixing between supply and leakage flows (ex, $\rightarrow$ ex,1); and an isobaric exhaust cooling down or heating up (ex, $1 \rightarrow$ ex).

The mass flowrate swept by the expander is given as a function of the expander swept volume $V_{\mathrm{s}}$, rotational speed $N$, and leakage flowrate as

$$
\dot{M}=\dot{M}_{\text {in }}+\dot{M}_{\text {leak }}=\frac{\dot{V}_{\mathrm{s}}}{v_{\text {su }, 2}}+\dot{M}_{\text {leak }}=\frac{N \cdot V_{\mathrm{s}}}{v_{\text {su }, 2}}+\dot{M}_{\text {leak }}
$$

All of the leakage paths are lumped into one unique fictitious leakage path connecting the expander supply and exhaust. The leakage flowrate and the pressure drops are computed by reference to the isentropic flows through a simply convergent nozzle of cross-sectional areas $A_{\text {leak }}$ and $A_{\text {su }}$. Under- and over-expansion losses are described by splitting the expansion into an isentropic expansion and a constant-volume evolution, which yields the following expression for the internal expansion power

$$
\dot{W}_{\mathrm{in}}=\dot{M}_{\mathrm{in}}\left[\left(h_{\mathrm{su}, 2}-h_{\mathrm{ad}}\right)+r_{\mathrm{v}, \text { in }} \cdot v_{\mathrm{su}, 2}\left(P_{\mathrm{ad}}-P_{\mathrm{ex}, 2}\right)\right]
$$

The modelling assumes that the distinction can be done between mechanical losses $\dot{W}_{\text {loss, } 1}$ due to friction between moving elements (scrolls, journal bearings, Oldham coupling, thrust surface) and electromechanical losses $\dot{W}_{\text {loss, } 2}$ in the asynchronous machine

$$
\dot{W}=\dot{W}_{\text {sh }}-\dot{W}_{\text {loss }, 2}=\dot{W}_{\text {in }}-\dot{W}_{\text {loss, } 1}-\dot{W}_{\text {loss }, 2}
$$

Mechanical losses are computed on the basis of the mechanical efficiency of the compressor

$$
\dot{W}_{\text {loss }, 1}=\left(1-\eta_{\text {mec }}\right) \cdot \dot{W}_{\text {in }}
$$

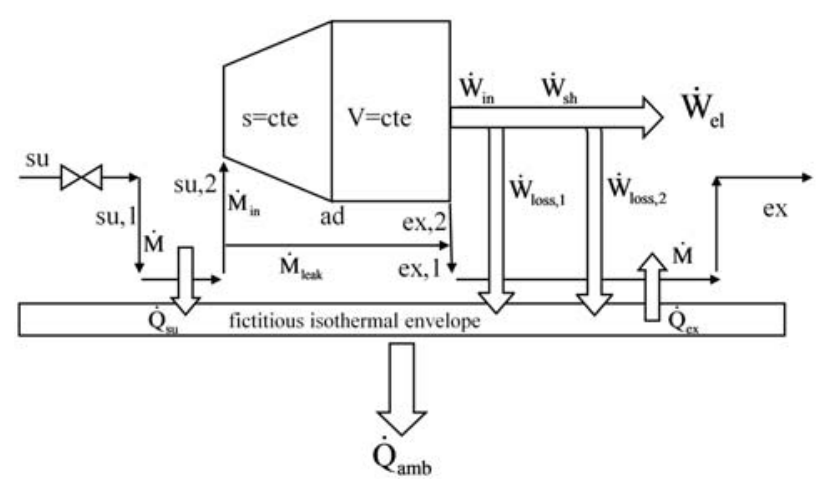

Fig. 9 Schematic representation of the expander simulation model 
Electromechanical losses were evaluated on the basis of the performance of the asynchronous machine in motor mode given by its manufacturer and can be expressed as a function of the shaft rotational speed

$$
\begin{aligned}
\dot{W}_{\text {loss }, 2}= & 199-0.4553 \cdot(3002-N) \\
& +0.03699 \cdot(3002-N)^{2}
\end{aligned}
$$

The rotational speed of the expander increases slightly with the power it produces, as a result of the speed sliding characteristic of the asynchronous machine. The following relationship has been derived from the performance given by the manufacturer of the asynchronous machine

$$
N=3007+0.02155 \cdot \dot{W}_{\mathrm{el}}+0.000002091 \cdot \dot{W}_{\mathrm{el}}^{2}
$$

Internal heat transfers are lumped into equivalent supply $\dot{Q}_{\text {su }}$ and exhaust $\dot{Q}_{\mathrm{ex}}$ heat transfers between the fluid and a fictitious shell of uniform temperature $T_{\text {shell }}$ (on the basis of overall heat transfer coefficients $A U_{\text {su }}$ and $A U_{\text {ex }}$ ). External heat transfer is described by an overall heat transfer coefficient $A U_{\mathrm{amb}}$. In steadystate regime, the shell temperature is given by

$$
\dot{Q}_{\mathrm{su}}+\dot{Q}_{\mathrm{ex}}-A U_{\mathrm{amb}} \cdot\left(T_{\mathrm{shell}}-T_{\mathrm{amb}}\right)+\dot{W}_{\mathrm{loss}, 1}+W_{\mathrm{loss}, 2}=0
$$

\subsection{Model calibration and validation}

The input variables of the expander simulation model are the supply and exhaust pressures and the supply temperature. The output variables are the mass flowrate displaced by the expander, its electrical power production, and the exhaust temperature. The model necessitates eight parameters that are tuned in order to best match the values of the output variables with the measurements. Identified parameters are listed in Table 3.

It was found that the best agreement between the predictions by the model and the measurements for the mass flowrate was obtained by considering a leakage area varying linearly with the supply pressure. There may be several underlying reasons such as the compliance mechanism.

Predictions by the model are compared with experimental data for the displaced mass flowrate, the electrical power, and the exhaust temperature in Figs 10,

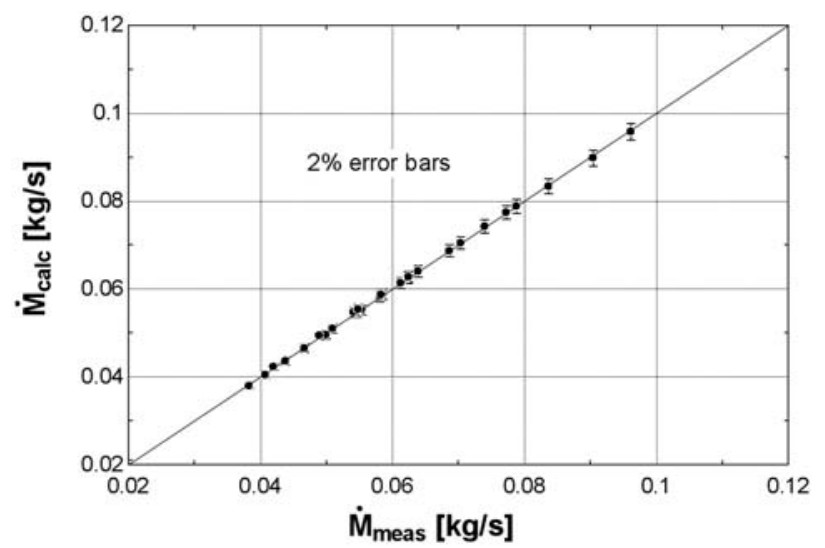

Fig. 10 Prediction by the model of the mass flowrate

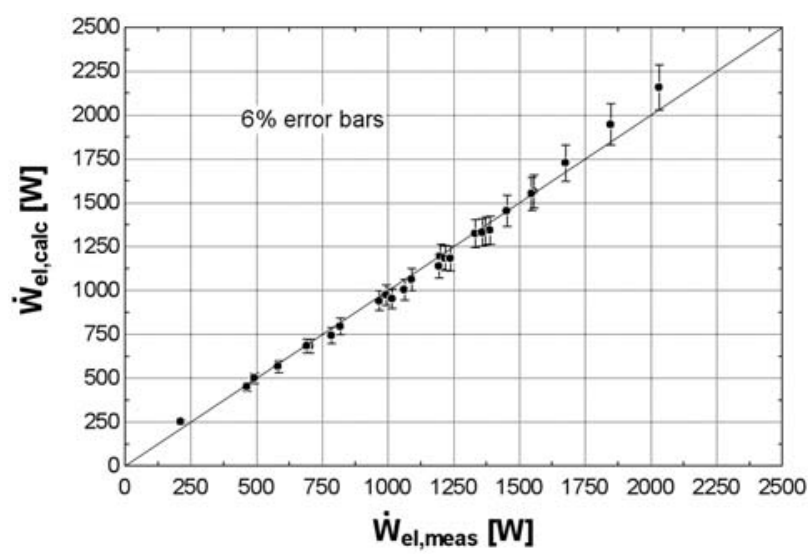

Fig. 11 Prediction by the model of the electrical output power

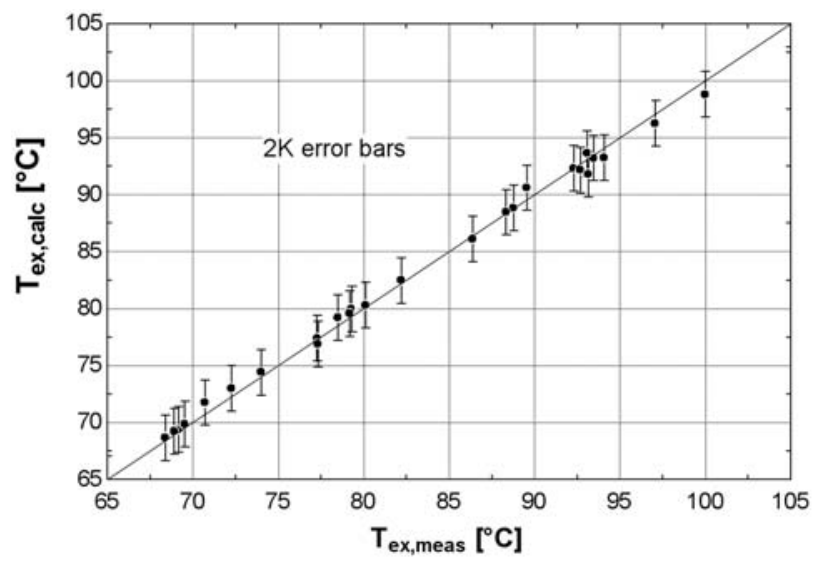

\begin{tabular}{|c|c|c|c|c|c|c|c|}
\hline$\overline{V_{\mathrm{s}}\left(\mathrm{cm}^{3}\right)}$ & $r_{\mathrm{v}, \text { in }}$ & $A_{\mathrm{su}}\left(\mathrm{mm}^{2}\right)$ & $A U_{\mathrm{su}}(\mathrm{W} / \mathrm{K})$ & $A U_{\mathrm{ex}}(\mathrm{W} / \mathrm{K})$ & $A U_{\mathrm{amb}}(\mathrm{W} / \mathrm{K})$ & $A_{\text {leak }}\left(\mathrm{mm}^{2}\right)$ & $\eta_{\text {mec }}(\mathrm{W})$ \\
\hline 22.4 & 2.85 & 30 & $30 \cdot\left(\frac{\dot{M}_{\text {cal }}}{0.1}\right)^{0.6}$ & $30 \cdot\left(\frac{\dot{M}_{\mathrm{cal}}}{0.1}\right)^{0.6}$ & 3.4 & $0.68-0.116 \cdot\left(10-P_{s u}(\right.$ bar $\left.)\right)$ & 0.90 \\
\hline
\end{tabular}

Fig. 12 Prediction by the model of the exhaust temperature

Table 3 Identified parameters of the scroll expander simulation model 
11, and 12, respectively. For almost all points, the maximal deviation between the prediction by the model and the measurements is 2 per cent for the mass flowrate, 6 per cent for the shaft power, and $2 \mathrm{~K}$ for the exhaust temperature. The discrepancies between predicted and measured values are most likely due to phenomena that were not taken into account. In order to take those effects into account, more intrusive measurements should be performed in the scroll pockets in order to accurately validate the model.

As shown in Fig. 13, the model also roughly predicts the heat transfer to the ambient. Despite the insulation of the machine, the ratio between ambient losses and the electrical power produced by the machine ranges from 15 to 40 per cent.

\section{POTENTIAL FOR IMPROVEMENT OF THE SCROLL EXPANDER}

The validated simulation model of the scroll expander is used to evaluate the impact of the different losses on its overall performance. Starting from a model that assumes a fully isentropic expansion, the different losses are introduced one after another. Results are shown in Fig. 14. The simulation is performed for a supply pressure of 12.61 bar (which corresponds to a saturation temperature of $100^{\circ} \mathrm{C}$ ) and a supply temperature of $110^{\circ} \mathrm{C}$. A pressure ratio of 10 corresponds to a saturation temperature close to $20^{\circ} \mathrm{C}$ at the exhaust pressure. These conditions are representative of those of the envisioned ORC application.

It can be observed that the electromechanical losses are significantly large. Further investigation should indicate to what extent these losses could be reduced by selecting a better adapted induction motor. Figure 15 shows the evolution of the motor efficiency and overall electromechanical efficiency with the electrical power produced by the expander.

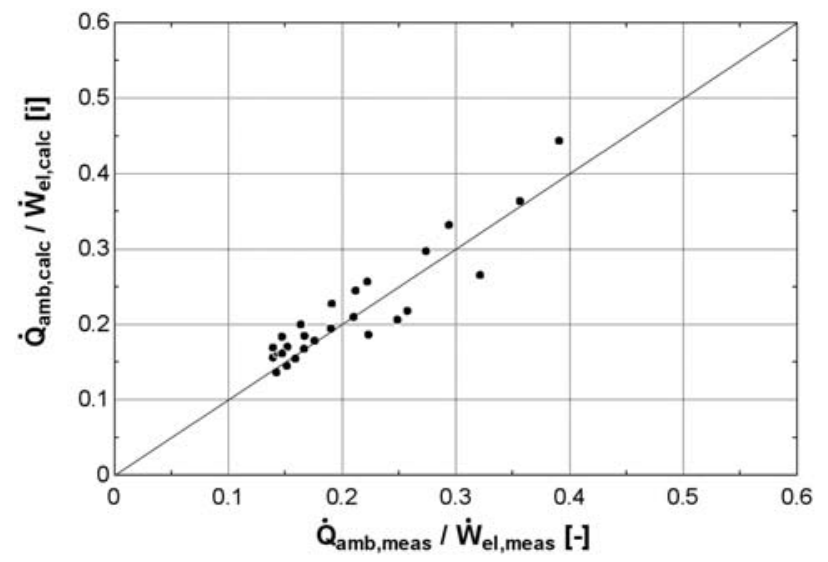

Fig. 13 Prediction by the model of the ambient losses
Internal leakages were also found to be non-negligible. However, the impact of these losses is largely reduced in comparison with the previously tested kinematically rigid configuration $[\mathbf{8}]$. This is due to both the axial and radial compliance mechanisms.

For the high pressure ratios, the under-expansion losses have a significant impact on the overall performance. A machine with a larger built-in volume ratio would yield better performance fore pressure ratios higher than 3.

\section{DIMENSIONLESS SIMULATION MODEL OF THE EXPANDER}

A semi-empirical thermodynamic model such as the one proposed in section 3 is well suited for the simulation of one particular machine. However, it cannot be used for bigger or smaller machines since the model parameters would need to be scaled according to a law that cannot be known without testing a large range of expanders with different swept volumes.

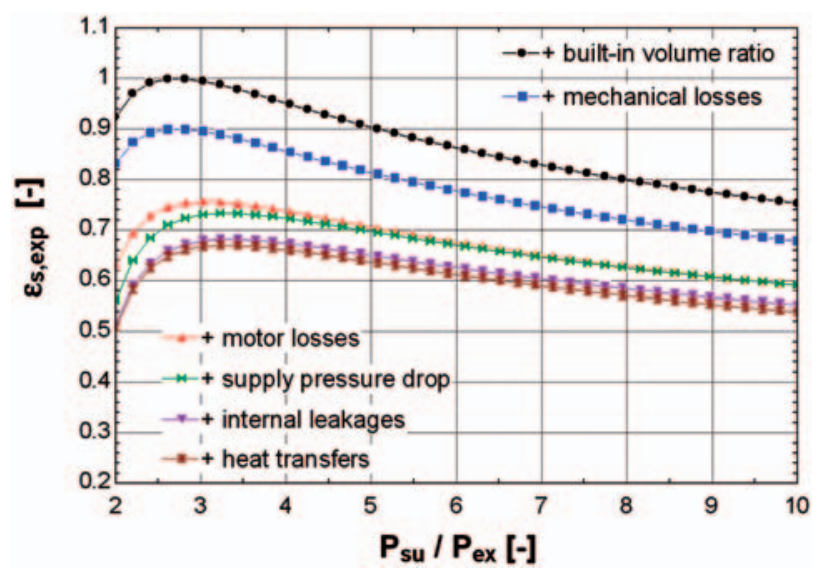

Fig. 14 Isentropic effectiveness versus pressure ratio

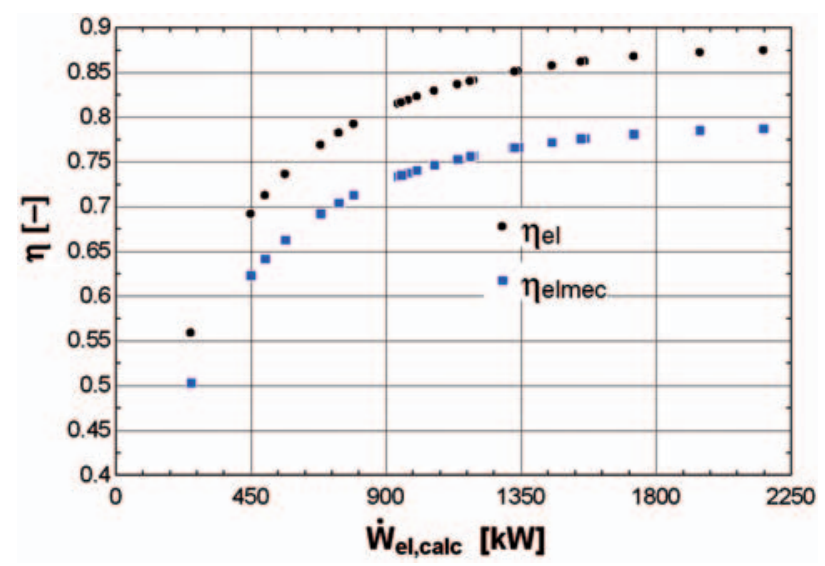

Fig. 15 Motor efficiency and electromechanical losses 
In order to obtain a generic non-dimensional efficiency curve, a polynomial fit of the effectiveness can be defined with carefully selected input variables. If ambient heat losses are neglected, scroll expanders can indeed be modelled by their isentropic effectiveness and by their filling factor as defined in equations (3) and (4).

In order to simulate realistic performance close to the actual experimental data, $\varepsilon$ and $\varphi$ are expressed as a polynomial law of the main working conditions. The two selected working conditions are the fluid inlet pressure $p_{\text {su }}$ and the pressure ratio over the expander $r_{\mathrm{p}}$ since they turned out to be the two main representative variables of the working conditions. The polynomial fits are expressed in the following form

$$
\begin{aligned}
& \sum_{i=0}^{n-1} \sum_{j=0}^{n-1} a_{i j} \cdot \ln \left(r_{\mathrm{p}}\right)^{i} \cdot \ln \left(p_{\mathrm{su}}\right)^{j}+a_{n 0} \cdot \ln \left(r_{\mathrm{p}}\right)^{n} \\
& \quad+a_{0 n} \cdot \ln \left(p_{\mathrm{su}}\right)^{n}=f\left(r_{\mathrm{p}}, p_{\mathrm{su}}\right)
\end{aligned}
$$

It is assumed that, when changing the scale of the expander (and thus the swept volume), the isentropic effectiveness and the filling factor remain similar if the pressure ratio and the inlet pressure are kept equal.

Since the number of parameters in this model is quite important (24 in total), the 27 measured working points are not sufficient to accurately determine all of them. Therefore, the semi-empirical model developed and validated in sections 3 and 4 is used to predict the performance on a wide range of working conditions: 800 different working points are calculated inside the following operating conditions

$$
2 \times 10^{5}<p_{\text {su }}<35 \times 10^{5}, \quad 2<r_{\mathrm{p}}<20
$$

The parameters of equation (13) are then determined using these 800 working points. For $\varepsilon$, a fifthorder $(n=5)$ polynomial fit is used, while for $\varphi$ a second-order $(n=2)$ polynomial fit turned out to be sufficient. Their values were respectively predicted with $R^{2}=99.31$ per cent and $R^{2}=99.62$ per cent.

Table 4 gives the parameters $a_{i j}$ of the polynomial fit. In order to check the validity of the correlations, the following values can be used: for $r_{\mathrm{p}}=3.54$ and $p_{\text {su }}=1.05 \times 10^{6}, \varphi=1.038$ and $\varepsilon=0.6868$.

\section{CONCLUSIONS}

The experimental investigation presented in this paper allowed for better characterization of the performance of a prototype of hermetic scroll expander derived from an existing heat pump compressor. The working fluid was HFC-245fa and the imposed operating conditions were similar to those of an envisioned ORC system.

The tested prototype achieved an excellent performance, higher than the one reported in the scientific literature: a maximum electrical isentropic effectiveness of 71.03 per cent was reached, compared with a maximum of 68 per cent in previous scientific works. An effectiveness of 77 per cent was also reported [13], but this efficiency was a mechanical isentropic efficiency, i.e. not taking into account the electromechanical losses of the generator.

Additional tests with larger oil mass fractions indicated that the isentropic effectiveness of the machine decreases with the quantity of oil. Further investigation must indicate with certainty the underlying reason.

Parameters of a semi-empirical simulation model of the scroll expander were then identified, based on the measurements. The model was found to predict with good accuracy the variables of first importance, such as the gas mass flowrate, the electrical power, and the exhaust temperature. The model was finally used to analyse the measured performance. Among others, it was found that the latter could be improved by using a downsized motor (the original one being sized for the compressor mode).

\section{FUNDING}

This research received no specific grant from any funding agency in the public, commercial, or not for

\begin{tabular}{|c|c|c|c|c|c|c|c|c|}
\hline \multirow{2}{*}{$\bar{\varepsilon}$} & & & & & & \multicolumn{3}{|l|}{$\varphi$} \\
\hline & & & & & & $j$ & & \\
\hline$i 0$ & 1 & 2 & 3 & 4 & 5 & 0 & 1 & 2 \\
\hline $\begin{array}{ll}0 & 6.34831061 \mathrm{E}+03 \\
1 & -4.62226605 \mathrm{E}+03 \\
2 & 5.18926734 \mathrm{E}+03 \\
3 & -2.71931292 \mathrm{E}+03 \\
4 & 486.73644600 \mathrm{E} 0 \\
5 & 53.18887310 \mathrm{E}-3\end{array}$ & $\begin{array}{l}-2.07325125 \mathrm{E}+03 \\
1.18102574 \mathrm{E}+03 \\
-1.40315596 \mathrm{E}+03 \\
765.49765200 \mathrm{E} 0 \\
-139.91256700 \mathrm{E} 0\end{array}$ & $\begin{array}{l}272.01506700 \mathrm{E} 0 \\
-111.05011200 \mathrm{E} 0 \\
141.44547800 \mathrm{E} 0 \\
-80.62867450 \mathrm{E} 0 \\
15.04869780 \mathrm{E} 0\end{array}$ & $\begin{array}{l}-17.99643220 \mathrm{E} 0 \\
4.54486911 \mathrm{E}+00 \\
-6.30866773 \mathrm{E}+00 \\
3.77077331 \mathrm{E}+00 \\
-718.76788400 \mathrm{E}-3\end{array}$ & $\begin{array}{l}602.74713900 \mathrm{E}-3 \\
-67.98375920 \mathrm{E}-3 \\
105.08861400 \mathrm{E}-3 \\
-66.08966540 \mathrm{E}-3 \\
12.86479100 \mathrm{E}-3\end{array}$ & $-8.20388944 \mathrm{E}-03$ & $\begin{array}{l}4.798 \\
-0.06549 \\
-0.00494\end{array}$ & $\begin{array}{l}-0.6231 \\
0.006766\end{array}$ & 0.02523 \\
\hline
\end{tabular}
profit sectors.

Table 4 Parameters of the polynomial model of the scroll expander 
(C) Authors 2011

\section{REFERENCES}

1 Yanagisawa, T., Fukuta, Y., Ogi, T., and Hikichi, T. Performance of an oil-free scroll-type air expander. In Proceedings of the IMechE Conference Transactions on compressors and their systems, 2001, pp. 167-174 (Professional Engineering Publications Limited, London).

2 Manzagol, J., d'Harboullé, P., Claudet, G., and Gistau Baguer, G. Cryogenic scroll expander for Claude cycle with cooling power of 10 to 100 watts at $4.2 \mathrm{~K}$. In Advances in cryogenic engineering, Proceedings of the Cryogenic Engineering Conference - CEC AIP Conference Proceedings 613, 2002, pp. 267-274 (American Institute of Physics).

3 Huff, H.-J. and Radermacher, R. $\mathrm{CO}_{2}$ compressorexpander analysis: Final report, report no. ARTI21CR/611-10060-01, Air-Conditioning and Refrigeration Technology Institute, Arlington, Virginia, 2003.

4 Xiaojun, G., Liansheng, L., Yuanyang, Z., and Pengcheng, S. Research on a scroll expander used for recovering work in a fuel cell. Int. J. Thermodyn., 2004, 7, 1-8.

5 Hugenroth, J., Braun, J., Groll, E., and King, G. Experimental investigation of a liquid-flooded Ericsson cycle cooler. International Journal of Refrigeration 31, 2008, 1241-1252.

6 Aoun, B. and Clodic, D. Theoretical and experimental study of an oil-free scroll type vapor expander. In Proceedings of 19th International Compressor Engineering Conference at Purdue (West Lafayette, IN, USA), July 14-17, 2008, Purdue University.

7 Peterson, R. B., Wang, H., and Herron, T. Performance of a small-scale regenerative Rankine power cycle employing a scroll expander. Proc. IMechE, Part A: J. Power and Energy, 2008, 222, 271-282.

8 Lemort, V., Quoilin, S., Cuevas, C., and Lebrun, J. Testing and modeling a scroll expander integrated into an organic Rankine cycle. Appl. Therm. Engng., 2009, 29, 3094-3102.

9 Quoilin, S., Lemort, V., and Lebrun, J. Experimental study and modeling of an organic Rankine cycle using scroll expander. Appl. Energ., 2010, 87, 1260-1268.

10 Declaye, S., Quoilin, S., and Lemort, V. Design and experimental investigation of a small-scale organic Rankine cycle using a scroll expander. In Proceedings of the 20th International Compressor Engineering Conference at Purdue (West Lafayette, IN, USA), July 12-15, 2010, Purdue University, 2512.

11 Zanelli R. and Favrat, D. Experimental investigation of a hermetic scroll expander-generator. In Proceedings of the 12th International Compressor Engineering Conference at Purdue (West Lafayette, IN, USA), July 19-22, 1994, Purdue University, pp. 459-464.
12 Kane, M., Larrain, D., Favrat, D., and Allani, Y. Small hybrid solar power system. Energy, 2003, 28, 1427-1443.

13 Wang, H., Peterson, R. B., and Herron, T. Experimental performance of a compliant scroll expander for an organic Rankine cycle. Proc. IMechE, Part A: J. Power and Energy, 2009, 223, 863-872.

14 Lemort, V., Cuevas, C., Lebrun, J., and Teodorese, I. V. Contribution à l'étude des cycles de Rankine de récupération de chaleur. In VIIIème Colloque Interuniversitaire Franco-Québécois sur la Thermique des Systèmes, May 28-30, 2007 (CIFQ, Canada, Montréal, Canada), paper no. ART-05-03.

15 Winandy, E., Saavedra, C., and Lebrun, J. Experimental analysis and simplified modelling of a hermetic scroll refrigeration compressor. Appl. Therm. Engng., 2002, 22, 107-120.

16 Klein, S. A. Engineering equation solver, F-Chart software, 2011 (Middleton, Wisconsin).

\section{APPENDIX}

\section{Notation}

$A$ cross-sectional area $\left(\mathrm{m}^{2}\right)$

$A U$ overall heat transfer coefficient $(\mathrm{W} / \mathrm{K})$

C specific heat $(\mathrm{J} / \mathrm{kgK})$

$h \quad$ specific enthalpy $(\mathrm{J} / \mathrm{kg})$

$\dot{M}$ mass flowrate $(\mathrm{kg} / \mathrm{s})$

$N$ rotational speed ( $\mathrm{r} / \mathrm{min})$

$p$ pressure $(\mathrm{Pa})$

$r_{\mathrm{v}, \text { in }}$ built-in volume ratio (-)

$v$ specific volume $\left(\mathrm{m}^{3} / \mathrm{kg}\right)$

$V_{\mathrm{s}} \quad$ swept volume $\left(\mathrm{m}^{3}\right)$

$\mathrm{s}$ specific entropy $(\mathrm{J} / \mathrm{kgK})$

$\dot{V}_{\mathrm{s}} \quad$ swept volume flowrate $\left(\mathrm{m}^{3} / \mathrm{s}\right)$

$x$ mass fraction $(-)$

$w$ specific work $(\mathrm{J} / \mathrm{kg})$

$\dot{W}$ power (W)

$\alpha$ factor of proportionality (-)

$\varepsilon \quad$ effectiveness (-)

$\eta \quad$ efficiency (-)

$\varphi \quad$ filling factor $(-)$

$$
\begin{aligned}
& \text { Subscripts } \\
& \text { ad } \text { adapted } \\
& \text { amb } \text { ambient } \\
& \text { bulb } \text { light bulb } \\
& \text { cal } \text { calorimeter } \\
& \text { coil } \text { cooling coil } \\
& \text { el } \text { electrical } \\
& \text { ex } \text { exhaust } \\
& \text { exp } \text { expander } \\
& \text { in } \text { internal } \\
& \text { leak } \text { leakage } \\
& \text { meas } \text { measured } \\
& \text { s } \text { isentropic } \\
& \text { sh } \text { shaft } \\
& \text { su } \text { supply }
\end{aligned}
$$

